\title{
Expression of Aquaporin Water Channels in the Rat Pituitary Gland
}

\author{
Sachi KUWAHARA ${ }^{1) *}$, Seishi MAEDA ${ }^{1)}$, Koichi TANAKA ${ }^{1)}$, Tetsu HAYAKAWA ${ }^{1)}$ and Makoto SEKI ${ }^{1)}$ \\ ${ }^{1)}$ Department of Anatomy, Hyogo College of Medicine, 1-1 Mukogawa-cho, Nishinomiya, Hyogo 663-8501, Japan
}

(Received 18 May 2007/Accepted 10 July 2007)

ABSTRACT. We investigated the expression of aquaporin (AQP) subtypes (AQP1-AQP9) in the rat pituitary gland by the reverse transcription-polymerase chain reaction (RT-PCR) and immunohistochemistry. Specific amplification by RT-PCR was observed in AQP1, AQP3, AQP4 and AQP5 but not in the others. AQP1 immunoreactivity was detected in the endothelial cells of blood vessels. No positive reaction to AQP3 was observed by immunohistochemistry, in spite of the detection of mRNA. AQP4 was localized in the supporting cells of the adenohypophysis and neurohypophysis. AQP5 was expressed in parts of the marginal cells in Rathke's residual pouch. These observations suggest that several subtypes of the AQP family are involved in regulation of water homeostasis in the rat pituitary gland.

KEY WORDS: pituitary gland, Rathke's residual pouch, water transport.

J. Vet. Med. Sci. 69(11): 1175-1178, 2007

Aquaporins (AQPs) are membrane proteins involved in water transport in many types of tissues. At least 13 subtypes, denoted AQP0-AQP12, have so far been identified in mammalian cells $[1,10,21,23]$. The biochemical characteristics and distribution of AQP1-AQP9 are well established. In the anterior pituitary, morphological studies have identified six different types of granulated cells, specifically hormone-producing cells and two types of non-granulated cells: folliculo-stellate cells, and marginal cells in Rathke's residual pouch [17]. The posterior pituitary contains the axons of neurosecretory cells and pituicytes [17]. Neither the expression of AQP nor the functional involvement in pituitary fluid homeostasis is completely understood, however. The pituitary of adult mammals is located ventral to the brain, and is attached to the hypothalamus by a stalk-like connection. Water homeostasis in the brain is of central physiologic and clinical importance. AQP4 is the predominant water channel in normal brain; it is strongly expressed in astrocyte plasma membranes, and has been shown to increase the water permeability of cell membranes isolated from mouse brain [6]. The localization of AQP4 at the cerebrospinal fluid (CSF)-brain and blood-brain interfaces suggests its involvement in fluid transport into and out of the brain $[11,16,18]$. Six other subtypes of AQP have been described in the rodent brain, known as AQP1, AQP3, AQP5, AQP7, AQP8 and AQP9 [2, 19]. The present study aims to provide a comprehensive description of AQP family members in the adult rat pituitary gland, including their locations.

Male Sprague-Dawley rats (10 weeks age) were obtained from Charles River Japan. The Animal Care and Use Committee of Hyogo College of Medicine approved our procedures. The rats were anesthetized with diethyl ether and sodium pentobarbital (40 mg/kg, i.p.). Rat tissues, pituitary

\footnotetext{
* Correspondence to: Kuwahara, S., Department of Anatomy, Hyogo College of Medicine, 1-1 Mukogawa-cho, Nishinomiya, Hyogo 663-8501, Japan.

e-mail: sachik@hyo-med.ac.jp
}

glands, kidneys, lacrimal glands, brains, testes and livers were removed and stored at $-80^{\circ} \mathrm{C}$ prior to reverse transcription-polymerase chain reaction (RT-PCR) analysis. For immunohistochemical analysis, pituitaries were immersed in $10 \%$ neutral formalin and embedded in paraffin. cDNA (derived from $2 \mu \mathrm{g}$ of total RNA by RTase) was amplified by PCR. The PCR reaction consisted 40 cycles of denaturation $\left(94^{\circ} \mathrm{C}, 30 \mathrm{sec}\right)$, annealing $\left(60^{\circ} \mathrm{C}\right.$ for AQP9 or $65^{\circ} \mathrm{C}$ for AQP1-AQP8, $30 \mathrm{sec})$ and extension $\left(72^{\circ} \mathrm{C}, 30 \mathrm{sec}\right)$. The primers used are specified in Table 1. PCR products were separated by electrophoresis on $2 \%$ agarose gel, and were examined with ethidium bromide. Immunohistochemistry was performed on $5 \mu \mathrm{m}$ thick sections. These were deparaffinized, heated to $121^{\circ} \mathrm{C}$ by autoclaving for $20 \mathrm{~min}$ in citrate buffer ( $\mathrm{pH} \mathrm{6.0)}$ in order to retrieve the antigen, and treated with $100 \%$ methanol containing $0.3 \% \mathrm{H}_{2} \mathrm{O}_{2}$ for $30 \mathrm{~min}$ at room temperature, to suppress the endogenous peroxidase. After washing with phosphate-buffered saline containing $0.05 \%$ Tween 20 (PBS/T), the sections were blocked with Block Ace ${ }^{\circledR}$ (Dainippon Sumitomo Pharma Co., Osaka, Japan) for $2 \mathrm{hr}$ at $37^{\circ} \mathrm{C}$, and incubated overnight with primary antibodies at $4{ }^{\circ} \mathrm{C}$. The antibodies used were: rabbit anti-rat AQP1 (2 $\mu \mathrm{g} / \mathrm{ml}$; Chemicon, CA, U.S.A.), rabbit anti-rat AQP3 (10 $\mu \mathrm{g} / \mathrm{ml}$; Calbiochem, CA, U.S.A.), rabbit anti-rat AQP4 (10 $\mu \mathrm{g} / \mathrm{ml}$; Sigma, MO, U.S.A.), and rabbit anti-rat AQP5 (3 $\mu \mathrm{g} / \mathrm{m} l$; Calbiochem). After washing with $\mathrm{PBS} / \mathrm{T}$, the sections were incubated with biotin-conjugated goat anti-rabbit IgG $(7.5 \mu \mathrm{g} / \mathrm{ml}$; Vector Laboratories Inc., CA, U.S.A.) for $1 \mathrm{hr}$ at $37^{\circ} \mathrm{C}$, followed by avidin-biotin-peroxidase complex (Vector ABC Elite kit, Vector Laboratories Inc.) for $1 \mathrm{hr}$ at $37^{\circ} \mathrm{C}$. The sections were washed with $\mathrm{PBS} / \mathrm{T}$ and incubated with a DAB substrate kit (Zymed Laboratories, CA, U.S.A.) for $10 \mathrm{~min}$. Negative controls for immunohistochemistry experiments were set up by omitting the primary antibodies or using non-immune rabbit IgG instead of anti-AQP antibodies; no positive reaction was observed (data not shown).

Specific amplification of AQP cDNAs in the pituitary 
Table 1. Rat aquaporin primers

\begin{tabular}{|c|c|c|c|}
\hline Gene & Primer & $\begin{array}{l}\text { Product size } \\
\text { (base pair) }\end{array}$ & $\begin{array}{c}\text { GenBank } \\
\text { Accession No. }\end{array}$ \\
\hline \multirow[t]{2}{*}{ AQP1 } & 5'-GGACAATGTGAAGGTGTCACTGGC-3' & 499 & L07268 \\
\hline & 5'-CCAGAAAATCCAGTGGTTTGAGAA-3' & & \\
\hline \multirow[t]{2}{*}{ AQP2 } & 5'-GGGCCAGCTCCCCACCCTCTG-3' & 500 & D13906 \\
\hline & 5'-ATCATCAAACTTGCCAGTGAC-3' & & \\
\hline \multirow[t]{2}{*}{ AQP3 } & 5'-GTTCCGTGGCTCAAGTGGTGC-3' & 500 & D17695 \\
\hline & 5'-GCCCATGGAGGTCCCAATGAC-3' & & \\
\hline \multirow[t]{2}{*}{ AQP4 } & 5'-CCATTAACTGGGGTGGCTCAG-3' & 500 & U14007 \\
\hline & 5'-AACTGCAGGGCCAAAGGATCG-3' & & \\
\hline \multirow[t]{2}{*}{ AQP5 } & 5'-CAGCACTCAAGTGGCCCTCGGCTC-3' & 478 & U16245 \\
\hline & 5'AAAGATCGGGCTGGGTTCATGGAA-3' & & \\
\hline \multirow[t]{2}{*}{ AQP6 } & 5’-ACGTTTTCTTTGGTGTGGGCT-3’' & 500 & AF083879 \\
\hline & 5'-AGGGCCGAAGGAGCGAGCTGG-3' & & \\
\hline \multirow[t]{2}{*}{ AQP7 } & 5'-TTGGCCTTGGTTCCGTGGCTC-3’ & 500 & AB000507 \\
\hline & 5'-GGACACCCCAAGAACGCAAAC-3' & & \\
\hline \multirow[t]{2}{*}{ AQP8 } & 5'-GAGCAGTACATACAACCGTGTGTG-3' & 600 & AB005547 \\
\hline & 5'-CCAGTAGATCCAATGGAAGTCCCA-3' & & \\
\hline \multirow[t]{2}{*}{ AQP9 } & 5'-TTATAATGATTGTCCTTGGAT-3' & 500 & AB013112 \\
\hline & 5'-GATCAGGAGGCTAATGACAAC-3' & & \\
\hline
\end{tabular}

Reference [4].

gland was observed for AQP1, AQP3, AQP4 and AQP5, but not AQP2, AQP6, AQP7, AQP8 or AQP9; positive controls of each AQP were detected (Fig. 1)

Location of AQPs whose mRNAs were detected by RTPCR in the pituitary glands was examined by immunohistochemistry. AQP1 was distributed widely in the endothelial cells of the blood vessels (Fig. 2a) throughout the anterior and posterior lobe. AQP1 was also expressed strongly in the erythrocytes. AQP1 has previously been identified in endothelial cells of many organs, such as the brain and lung, under normal conditions [9, 15, 22]. AQP1 may be involved in water transfer across the vascular wall in the pituitary gland.

We did not detect any specific immunohistochemical staining of AQP3 (data not shown), but we found weak expression in the rat pituitary gland according to RT-PCR. In situ hybridization studies might also determine the locations of AQP3 expression in the pituitary gland.

AQP4 was reactive to a number of cells in the pituitary gland. These AQP4-positive cells were stellate in shape, with elongated cytoplasmic processes among the endocrine cells in the anterior lobe (Fig. 2b). These highly asymmetric cells are believed to be folliculo-stellate cells [12], but further investigations are needed to identify the cell type. The marginal cells in Rathke's residual pouch were reactive to AQP4 (Fig. 2b). AQP4 was also located throughout the neurohypophysis (Fig. 2c). The border of the pars intermedia and posterior was especially strongly immunoreactive to AQP4 (Fig. 2c). Previous work has found that AQP4 is expressed in ependymal cells and astrocytes in the brain and spinal cord, and particularly at sites of fluid transport at the ependymal surface in contact with the CSF in the ventricular system $[11,14,16,18]$. Some ultrastructural and immunocytochemical studies found that marginal cells and ependymal cells have very similar characters $[3,12]$. AQP4 may

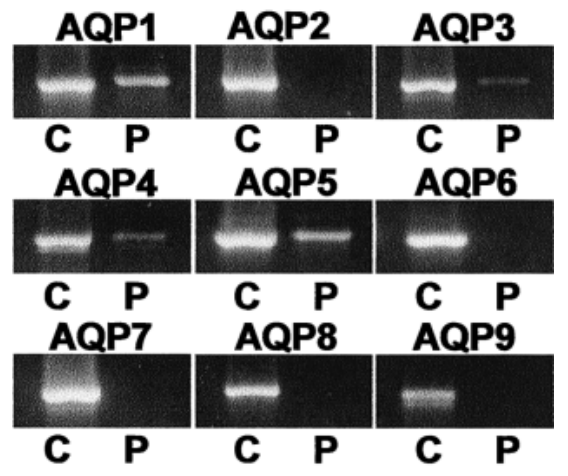

Fig. 1. RT-PCR analysis of AQPs in the rat pituitary gland. The right lane of each panel (P) corresponds to amplifications performed using pituitary gland cDNA template. Expression of AQP1, AQP3, AQP4 and AQP5 mRNA was identified. No positive amplification was observed for AQP2, AQP6, AQP7, AQP8 and AQP9. Positive controls of each AQP in the left lanes (C) represent amplification cDNAs from kidney (AQP1, AQP2, AQP3 and AQP6), brain (AQP4), lacrimal gland (AQP5), testis (AQP7) and liver (AQP8 and AQP9).

therefore be involve in osmoregulation thorough the marginal layers and folliculo-stellate cells in the pituitary gland, such as the ependymal cells and astrocytes in the brain. In the posterior pituitary, the AQP4-immunoreactive cells may be the pituicytes, which are similar in structure and function to the astrocytes of the central nervous system.

AQP5 is present mainly in the acinar secretory cells of exocrine glands $[7,8,13,20]$, and is also observed in astrocytes [24]. The marginal cells in Rathke's pouch were also 


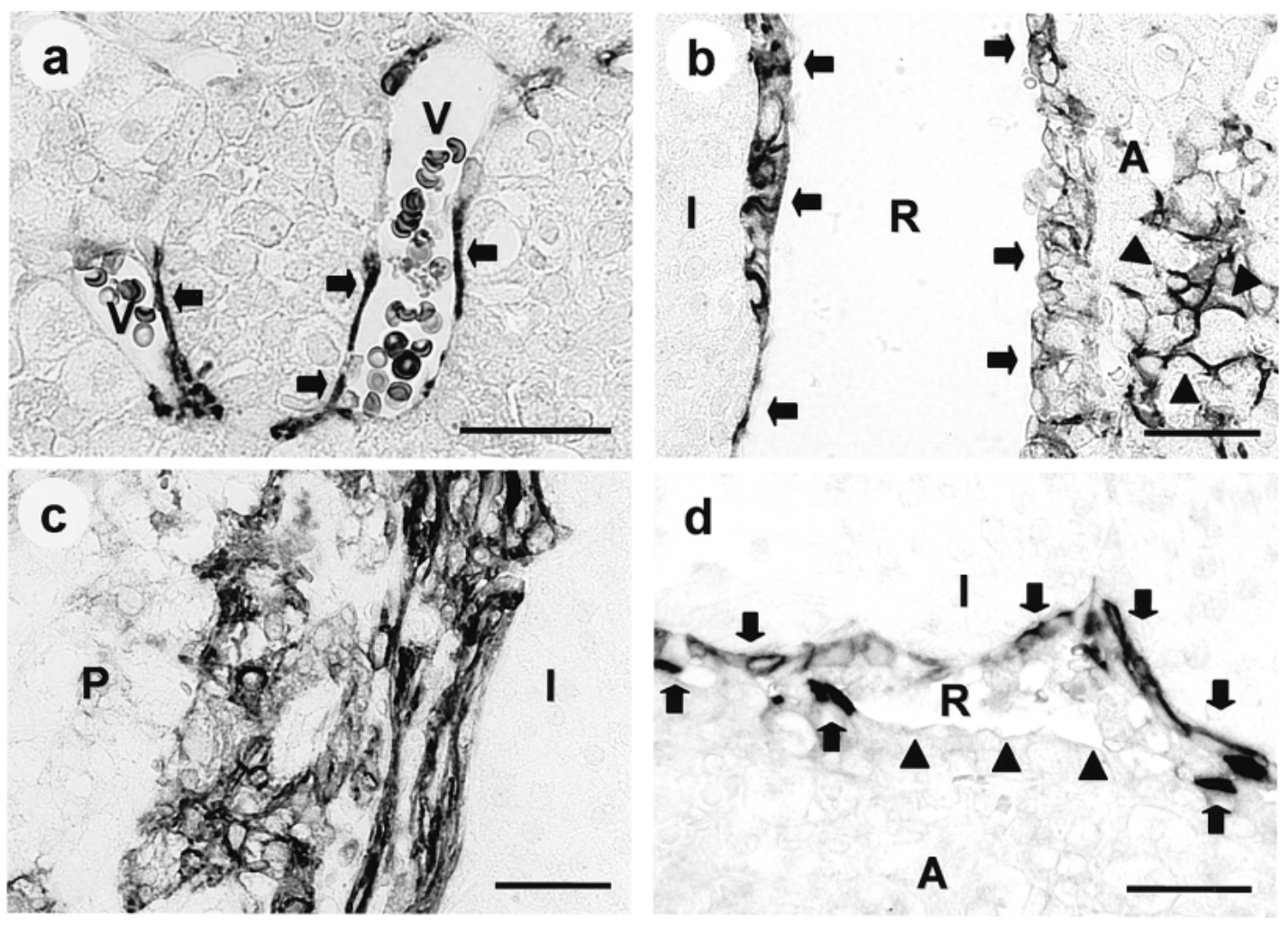

Fig. 2. Immunohistochemistry of AQP1 (a), AQP4 ((b) and (c)) and AQP5 (d) in the rat pituitary gland. Endothelial cells of the blood vessels are positive for AQP1 (a, arrows). AQP1 was also expressed strongly in the erythrocytes. AQP4 is detected in the marginal cells in Rathke's residual pouch (b, arrows), in anterior supporting cells (b, arrowheads), and in posterior cells (c). The marginal cells (d, arrows) are positive for AQP5, but not all of them are reactive (d, arrowheads). Abbreviations: A, anterior lobe; I, intermediate lobe; P, posterior lobe; R, Rathke's residual pouch; V, blood vessels. Scale bars $=30 \mu \mathrm{m}$

positive for AQP5, but unlike AQP4 not all of these cells were positive (Fig. 2d). This suggests that two types of cells are present in the marginal layers: AQP5-positive and AQP5-negative ones. The marginal cells may regulate water transport with AQP4 and AQP5. It is not known, however, what is the functional difference between these $\mathrm{AQPs}$, and how a dual-regulation system of the two types of marginal cells is significant in the pituitary gland.

In the adult brain, AQP9 is expressed in astrocytes and appears to play an important role in water transfer [2]. Although AQP9 expression has been also reported in anterior pituitary cells according to immunohistochemistry [5], we were unable to detect AQP9 mRNA in the rat pituitary gland by RT-PCR analysis.

In summary, we found several AQPs in rat pituitary glands. The expression pattern suggests that several different members of the AQP family take part in water homeostasis involving the rat pituitary gland. We believe that this is the first report on the pattern of AQPs expression in mammalian pituitary glands. A fuller study would provide further clues to the role of AQPs in fluid homeostasis in the pituitary endocrine system.

ACKNOWLEDGMENTS. The authors thank Dr. Fumi- hiko Sasaki (Osaka Prefecture University, Japan) for advice. We also thank Ms. Megumi Hatta and Mr. Katsumi Gion for their secretarial and technical assistance. This study was supported partly by a Grant-in-Aid for Researchers from Hyogo College of Medicine.

\section{REFERENCES}

1. Agre, P., King, L.S., Yasui, M., Guggino, W. B., Ottersen, O.P. and Fujiyoshi, Y. 2002. J. Physiol. 542: 3-16.

2. Badaut, J., Lasbennes, F., Magistretti, P.J. and Regli, L. 2002. J. Cereb. Blood Flow Metab. 22: 367-378.

3. Correr, S. and Motta, P.M. 1981. Cell Tissue Res. 215: 515529.

4. Ko, S.B.H., Naruse, S., Kitagawa, M., Ishiguro, H., Furuya, S., Mizuno, N., Wang, Y., Yoshikawa, T., Suzuki, A., Shimano, S. and Hayakawa, T. 2002. J. Physiol. Gastrointest. Liver Physiol. 282: G324-G331.

5. Li, C., Hirooka, Y., Honda, R., Morikawa, R., Yatoh, M., Gotoh, M. and Nogimori, T. 2005. Int. J. Tissue React. 27: 5158.

6. Ma, T., Yang, B., Gillespie, A., Carlson, E.J., Epstein, C.J. and Verkman, A.S. 1997. J. Clin. Invest. 100: 957-962.

7. Matsuzaki, T., Suzuki, T., Koyama, H., Tanaka, S. and Takata, K. 1999. Cell Tissue Res. 295: 513-521.

8. Matsuzaki, T., Tajika, Y., Suzuki, T., Aoki, T., Hagiwara, H. 
and Takata, K. 2003. Arch. Histol. Cytol. 66: 307-315.

9. Mobasheri, A. and Marples, D. 2004. Am. J. Physiol. Cell Physiol. 286: C529-C537.

10. Morishita, Y., Sakube, Y., Sasaki, S. and Ishibashi, K. 2004. J. Pharmacol. Sci. 96: 276-279.

11. Nagelhus, E.A., Mathiisen, T.M. and Ottersen, O.P. 2004. Neuroscience 129: 905-913.

12. Nakajima, T., Yamaguchi, H. and Takahashi, K. 1980. Brain Res. 191: 523-531.

13. Nejsum, L.N., Kwon, T-H., Jensen U.B., Fumagalli, O., Frøkiaer, J., Krane, C.M., Menon, A.G., King, L.S., Agre, P.C. and Nielsen, S. 2002. Proc. Natl. Acad. Sci. U.S.A. 99: 511516.

14. Nicchia, G.P., Srinivas, M., Li, W., Brosnan, C.F., Frigeri, A. and Spray, D. C. 2005. FASEB J. 19: 1674-1676.

15. Nielsen, S., Smith, B.L., Christensen, E.I. and Agre, P. 1993. Proc. Natl. Acad. Sci. U.S.A. 90: 7275-7279.

16. Nielsen, S., Nagelhus, E. A., Amiry-Moghaddam, M., Bourque, C., Agre, P. and Ottersen, O. P. 1997. J. Neurosci.
17: $171-180$.

17. Norris, D.O. 2006. Vertebrate Endocrinology, 4th ed., Elsevier Academic Press, Massachusetts.

18. Rash, J.E., Yasumura, T., Hudson, C.S., Agre, P. and Nielsen, S. 1998. Proc. Natl. Acad. Sci. U.S.A. 95: 11981-11986.

19. Shin, I., Kim, H.J., Lee, J.E. and Gye M.C. 2006. Neurosci. Lett. 409: 106-111.

20. Song, Y., Sonawane, N. and Verkman, A.S. 2002. J. Physiol. 541: $561-568$

21. Takata, K., Matsuzaki, T. and Tajika, Y. 2004. Prog. Histochem. Cytochem. 39: 1-83.

22. Verkman, A.S. 2002. J. Anat. 200: 617-627.

23. Verkman, A.S. 2005. Rev. Physiol. Biochem. Pharmacol. 155: $31-55$.

24. Yamamoto, N., Yoneda, K., Asai, K., Sobue, K., Tada, T., Fujita, Y., Katsuya, H., Fujita, M., Aihara, N., Mase, M., Yamada, K., Miura, Y. and Kato, T. 2001. Brain Res. Mol. Brain Res. 90: 26-38. 